\title{
Importância nutricional e metabólica da fibra na dieta de equinos
}

\section{Roberta Ariboni Brandi ${ }^{1}$, Carlos Eduardo Furtado²}

\author{
${ }^{1}$ Faculdade de Zootecnia, Universidade Estadual Paulista, UNESP Campus Experimental de Dracena. \\ 2 Departamento de Zootecnia, Universidade Estadual de Maringá.
}

RESUMO - O equino é um herbívoro não ruminante capaz de suprir grande parte ou a totalidade da sua demanda nutricional pela ingestão de gramíneas. Apresenta a região ceco-cólica bastante desenvolvida, sendo este o principal sítio de fermentação. Este processo também ocorre na região aglandular do estômago, porém a produção de ácidos graxos voláteis é inferior, quando comparado ao intestino grosso. O conhecimento do sítio de aproveitamento de cada ingrediente é de suma importância para a combinação dos mesmos, favorecendo o ótimo aproveitamento de cada um deles e evitando excessos que podem ser prejudiciais ao metabolismo do equino. O estudo atual do fracionamento de carboidratos, por mais que não seja adaptado a fisiologia e metabolismo dos equinos, nos fornece informações sobre as diferentes frações que o compõem e com isso pode-se inferir sobre a produção de energia por cada fração gerada. A manutenção de equinos em pastejo ou sob o fornecimento de feno ou alimentos volumosos é essencial para a manutenção da atividade e saúde do seu trato digestório. O aporte mínimo de 12\% de FDN garante tal situação. Atualmente, com o objetivo de aumentar a disponibilidade de energia, ingredientes como a polpa cítrica, polpa de beterraba e casca de soja, vem sendo utilizados nas formulações. Estes ingredientes de fermentação mais rápida e fácil, são uma alternativa segura para elevar a concentração energética da dieta de equinos, por proporcionar a diminuição do aporte de amido na dieta de equinos. Sabe-se entretanto, que com a elevação na qualidade do volumoso, maiores concentrações de carboidratos solúveis e de rápida fermentação são encontrados disponíveis ao longo do trato digestório dos equinos levando a alguns distúrbios metabólicos como a laminite e a sensibilidade a insulina. Com o correto manejo dos animais em pastejo e conhecimento do ciclo da planta é possível minimizar tais problemas. Objetivou-se revisão da ação fisiológica e metabólica das diferentes frações fibrosas, em cada compartimento do trato digestório, bem como destacar os ingredientes volumosos com suas diversas frações, os quais possibilitam sugerir manejo alimentar adequado para os equinos.

Palavras-chave: equinos, fibra, metabolismo, nutrição, trato digestório

\section{Nutritional and metabolic importance of fiber in the horse diet}

\begin{abstract}
The equine is a non herbivore ruminant that is able to fully provide its nutritional need by the grass intake. Equines show the cecum and colon region plenty developed as their principal fermentation site. Such process either happens in the non glandular stomach region, but the volatile fatty acids production is inferior then the production in the -hindgut. To meet the optimum use of the mix of ingredients, and to avoid excess there are harmful to the equine metabolism, it is important to know the ingredients digestion site. The recent carbohydrate fragmentation's study, even if it's not totally adapted to the equine metabolism and physiology, can provide information regarding the different carbohydrate fraction, that lead to infer data about the energy produced by each fraction. Feeding equines in pasture, or with hays or forage fed is essential to keep the digestive tract in activity and healthy, and to guarantee such condition, it necessary to provide at least $12 \%$ of NDF. Nowadays, ingredients such as citric pulp, beet pulp, soybean hulls, are used in the formulations to increase the energy's availability. The above mentioned ingredients, that present fast and easy fermentation, are a safe alternative to increase the energetic concentration in the equine diet, due to the decrease of the starch supply in such procedure. It's known that, with the increase in fibrous fed quality, higher amounts of soluble carbohydrates with fast fermentation are available along all equine digestive tract generating some metabolic disturbs such as laminits and insulin sensibility. With the correct equine pasture handling and the knowledge of the plant cycle it's possible to reduce such problems. The aim of this study is review the physiologic and metabolic action of different fibrous fraction in each digestive compartment tract of the equine diet, likewise to list the main studies of fibrous fed fractions with their fractions, which allow to suggest appropriate feed handling for equines.
\end{abstract}

Key Words: equine, fiber, gastrintestinal tract, metabolism, nutrition 


\section{Introdução}

O equino é um herbívoro não ruminante capaz de suprir grande parte ou a totalidade da sua demanda nutricional pela ingestão de gramíneas. Apresenta a região ceco-cólica bastante desenvolvida, sendo este o principal sítio de fermentação. Este processo também ocorre na região aglandular do estômago, porém a produção de ácidos graxos voláteis é inferior, quando comparado ao intestino grosso. O conhecimento do sítio de aproveitamento de cada ingrediente é de suma importância para a combinação dos mesmos, favorecendo o ótimo aproveitamento de cada um deles e evitando excessos que podem ser prejudiciais ao metabolismo do equino. O estudo atual do fracionamento de carboidratos, por mais que não seja adaptado a fisiologia e metabolismo dos equinos, nos fornece informações sobre as diferentes frações que o compõem e com isso pode-se inferir sobre a produção de energia por cada fração gerada.

Adaptações anátomo-fisológicas dos equinos a utilização da fração fibrosa dos alimentos

\section{Boca}

A entrada do trato digestório é formada por lábios fortes e extremamente móveis. O cavalo apreende o alimento principalmente com os lábios e a língua, e no pastoreio ou na ingestão de substâncias mais firmes (ramos e tubérculos) também são usados os incisivos (superiores e inferiores), o que lhe permite pastar próximo ao solo, cortando a forragem. O lábio superior é utilizado para colocar a forragem entre os dentes do cavalo. O cavalo normalmente só mastiga de um lado, com alterações periódicas (60-80 movimentos mastigatórios por minuto). Para fenos com fibras longas o número de movimentos mastigatórios por minuto $(\mathrm{mmm})$ varia de 73-92 (mmm), assim sendo $1 \mathrm{~kg}$ de feno longo requer cerca de 3.000-3.500 movimentos mastigatórios, enquanto $1 \mathrm{~kg}$ de feno requer 800-1.200 (mmm). A velocidade de ingestão dos equinos depende da natureza do alimento, podendo levar cerca de 10 minutos para ingerir $1 \mathrm{~kg}$ de aveia ou alimento peletizado, e até 40-50 minutos para ingerir $1 \mathrm{~kg}$ de feno. O cavalo ingere cerca de 2,5 mg de MS por kg de peso metabólico para cada mastigação. Durante a mastigação o alimento é triturado, o volumoso é dividido em partículas de no máximo $2 \mathrm{~mm}$ de diâmetroe $1-4 \mathrm{~mm}$ de comprimento (1,6 $\mathrm{mm}$ de comprimento) sendo esta divisão essencial para a manutenção do transito intestinal normal. Alimento de fibras curtas ou volumoso excessivamente picado $(<2 \mathrm{~cm})$ podem ser deglutidos sem mastigação e com isso causar obstipações. A prensagem promovida pelos molares libera proteínas e açúcares que podem ser rapidamente utilizados no estômago e intestino delgado. A saliva é produzida e misturada com o alimento somente durante a mastigação. Assim o tempo de ingestão tem grande influência sobre este fator. Cavalos produzem cerca de $40-90 \mathrm{ml}$ de saliva por minuto, quantidade variável com a natureza do alimento. A saliva não contém enzimas digestivas, mas contém expressivas quantidades de minerais e bicarbonato (50 $\mathrm{mEq} / \mathrm{L}$ ), que provavelmente servem para neutralizar os ácidos formados na porção inicial do estômago, além de umidecer o alimento e favorecer o trânsito e a penetração do suco gástrico no bolo alimentar (Meyer, 1997 e Frape, 2008).

Trato digestório dos equinos e seus órgãos associados

Segundo Frape (2008) em cavalos adultos, o peso médio dos tecidos do trato digestório (TD) varia de 45 a $50 \mathrm{~g} / \mathrm{kg}$ de peso vivo e o fígado $10 \mathrm{~g} / \mathrm{kg}$ de peso vivo. Após a alimentação o fígado do mamífero aumenta, provavelmente atribuído ao armazenamento de glicose e fluxo sangüíneo. O consumo de forragem tem menos impacto sobre o glicogênio hepático, assim sendo, após uma refeição de feno o fígado aumenta apenas $3 / 4$ do peso quando comparado com dietas após alimentação mista (concentrado + volumoso). Em descanso, cerca de 30\% do debito cardíaco circula no sistema porta hepático.

O intestino delgado (ID) do cavalo não aumenta materialmente de comprimento a partir da quarta semana de vida do cavalo, enquanto o intestino grosso aumenta com a idade e o colón até 20 anos, pelo menos. As porções distais continuam a aumentar até uma idade maior do que as regiões proximais. Esse incremento reflete o aumento na dependência de forragem nos animais mais velhos.

Dentre as secreções aportadas ao ID, destacam-se o suco pancreático, que tem como característica marcante a baixa concentração de enzimas e a secreção constante, mediado pela secretina. Embora a secreção seja contínua, esta aumenta em 4 a 5 vezes quando se oferece o alimento pela primeira vez. O estímulo à secreção não aumenta a concentração de bicarbonato, como ocorre nas demais espécies (Frape, 2008). O cavalo não possui vesícula biliar, assim a secreção é contínua e cessa apenas quanto o jejum é superior a $48 \mathrm{~h}$. A bile, juntamente com o suco pancreático, eleva o $\mathrm{pH}$ da digesta para 7 na região duodenal.

\section{Estômago}

O estômago do cavalo é um órgão relativamente pequeno, com cerca de $10 \%$ do TD, adaptado a recepção contínua de pequenas quantidades de alimento. A maior parte da digesta fica retida por um período relativamente 
curto, cerca de 2 a 6 horas, mas este órgão dificilmente fica totalmente vazio.

O eqüino apresenta esfíncteres bastante desenvolvidos que o impedem de regurgitar. Quase metade da superfície mucosa é recoberta por epitélio aglandular, e a porção mucosa fica restrita a regiões fúndicas e pilóricas, onde são secretados ácido clorídrico, pepsina e hormônio polipeptídico e gastrina, respectivamente. A secreção hormonal é iniciada pela refeição, e nos equinos a liberação esta vinculada a distensão gástrica e não à visualização do alimento. Maiores secreções de gastrina são observadas quando os equinos são alimentados de feno ad libitum. Dietas ricas em grãos promovem aumento rápido do $\mathrm{pH}$ devido a secreção mais lenta de gastrina na presença de grãos, quando comparados a volumosos. Como o estômago é relativamente pequeno e o tempo de permanência do alimento é relativamente curto, o grau de digestão de proteínas é baixo.

$\mathrm{Na}$ região aglandular (saccus caecus) ocorre à fermentação sob atividade de microrganismos que degradam açúcares, amido e proteínas. Segundo Frape (2008) o resultado é a produção de ácido lático (23-27 mmol/l para concentrado e $14 \mathrm{mmol} / \mathrm{l}$ para capim velho), ácidos graxos de cadeia curta, sendo $95 \%$ ácido acético $(10 \mathrm{mmol} / 1$ para concentrados e $8,5 \mathrm{mmol} / \mathrm{l}$ para capim velho) e pequenas quantidades de gases $\left(\mathrm{CO}_{2}, \mathrm{CH}_{4}\right.$ e $\left.\mathrm{H}_{2}\right)$. Na região média do estômago o pH varia entre 5 e 6 , enquanto na região pilórica pode atingir 2,6 em dietas exclusivas de feno, o que não ocorre com dietas a base de concentrado. Meyer (1995) sugere não administrar mais do que $0,4 \%$ de concentrado/ Kg PV por refeição e utilizar sempre concentrados e volumosos de alta qualidade higiênica, enquanto Hoffman (2003) sugere o fornecimento máximo de $0,2 \% \mathrm{Kg} / \mathrm{PV}$ por refeição de amido ou fibras de fácil fermentação por refeição.

Yuki et al (2000) observou que a porção aglandular do estômago do eqüino é povoado por bactérias gram positivas, sendo as principais encontradas Lactobacillus salivarius, L. crispatus, L. reuteri e L. agilis. Foi observado que estas bactérias não têm a capacidade de se fixar na mucosa e que não formam associações com outras bactérias, porém ainda não foi esclarecido qual é a implicação destas situações. Estes pesquisadores reportaram que a presença de Lactobacillus inibe as bactérias potencialmente patogênicas de se fixarem na mucosa, possivelmente por competição pelo substrato.

Fombelle et al. (2003) e Varloud et al. (2003) reportaram significante desaparecimento de matéria seca e amido no estômago. É também possível que as frutanas possam ser digeridas ou fermentadas no estômago, dados que concordam com os obtidos por Coenen et al (2006).

Hoffman (2003) cita que a presença de ácidos graxos (acetato, propionato e butirato) sugere que existe fermentação limitada no estômago, particularmente na região fúndica favorecendo a geração de ácido lático. O pequeno tempo de retenção estomacal e a queda brusca de $\mathrm{pH}$ da região fúndica para pilorica $(5,46$ para 2,7$)$ suporta uma fermentação simbólica, ou seja, de pequena dimensão sob condições normais.

Fombelle et al (2003) caracterizando o perfil microbiano e bioquímico dos diferentes segmentos do trato digestório do equinos, observou que o estômago tem a maior concentração de bactérias anaeróbicas $\left(1,4510^{9} \mathrm{UFC} / \mathrm{ML}\right)$, comparativamente ao intestino grosso (7,95 $\left.10^{7} \mathrm{UFC} / \mathrm{Ml}\right)$. Lactobacillus, streptococcus e bactérias produtoras/ utilizadoras de lactato colonizam todo o TD do eqüino, sendo o estômago e o ID os principais sítios destes microrganismos, situação que sugere grande interferência na digestão dos carboidratos prontamente disponíveis. Os Lactobacilli colonizam principalmente o estômago enquanto os streptococci estão mais homogeneamente distribuídos. A dieta influencia a concentração de Lactobacilli, sendo a dieta rica em grãos a apresentar a maior concentração, o que também ocorreu com os streptococci. A dieta pode, portanto influenciar o desenvolvimento dos microrganismos em cada parte do TD.

Muhonem (2008) cita que a mucosa do estomago tem capacidade de absorver os AGV nas regiões pilórica e gástrica, mas têm pequena capacidade de transportá-los para o sangue.

Varloud et al. (2007) mensurando a população de bactérias consumidoras de lactato no estômago, observou população de 3,18 a $5,38 \log 10 \mathrm{cfu} / \mathrm{ml}$, situação importante pois o produto final da utilização do lactato é a produção de propionato, além do consumo deste substrato favorecer a manutenção valores aceitáveis de $\mathrm{pH}$.

\section{Intestino delgado}

O intestino delgado (ID) do cavalo é relativamente curto, medindo cerca de 20 a 25 metros, em um cavalo de $450 \mathrm{~kg}$, o que representa cerca de $30 \%$ do TD. A velocidade de movimentação da digestão varia de $20 \mathrm{~cm} / \mathrm{min}$. a $30 \mathrm{~cm} /$ min. Assim o tempo médio de esvaziamento do ID é de 1,5 a 2 horas, para alimentos sólidos, enquanto para líquidos o tempo pode variar de 45 minutos a 1 hora. Estudo comparando cavalos alimentados ad libitum e cavalos alimentados após jejum de $12 \mathrm{~h}$, mostrou que os animais alimentados após jejum têm o tempo de transito do estômago ao ceco mais rápido (Meyer, 1995; Frape, 2008). 
A maioria das fontes energéticas de dietas para equinos encontra-se na forma de carboidratos, principalmente o amido de cereais, os quais apresentam cadeias longas e ramificadas de $\alpha$-D-glicose, as quais dependem da ação de á-amilase (secretada pelo pâncreas) e $\alpha$-glicosidases, também conhecidas como dissacaridases (secretadas pela mucosa intestinal do ID). Incluem também a sacarase e a dissacaridase, presentes em concentrações cinco vezes maiores do que a glicoamilase, capaz de digerir a sacarose. A sacarase atua principalmente no intestino delgado proximal e é similar a descrita em outras espécies não ruminates, fato que não ocorre com a atividade da maltase, a qual apresentase extremamente alta. A D-glicose e D-galactose são absorvidas de forma ativa ( $\mathrm{Na}+$ /glicose) e levadas ao sistema porta hepático.

À medida que a quantidade de amido aumenta na dieta, aumenta também a quantidade de amido que escapa da digestão pré-cecal. Existem evidências que mostram que pouco mais de $50 \%$ do amido é sujeito a digestão pré-cecal. Desta forma, não apenas o processamento, mas a quantidade de amido ingerido influencia diretamente na digestão. Quando amido não digerido alcança o íleo e o ceco, o pH desta região diminui, e o ácido lático e outros ácidos orgânicos são produzidos. Como o eqüino apresenta apenas $10 \%$ da secreção de amilase pancreática apresentada por um suíno, grandes quantidades de amido podem passar pelo ID sem serem aproveitadas, chegando assim ao intestino grosso (Pagan, 1998).

Segundo Frape (2008), no jejuno e íleo existe abundante população de bactérias gram-positivas anaeróbicas obrigatórias ( $10^{8}$ a $10^{9}$ bactérias/g). Hoffman (2003) cita que aparentemente existe fermentação na porção distal do intestino delgado, mas, ainda não é bem determinado se a fermentação neste segmento é independente da fermentação no intestino grosso ou se é atribuída ao refluxo do conteúdo do intestino grosso. A concentração de bactérias celulolíticas não excedeu 3,0 $510^{2} \mathrm{UFC} / \mathrm{Ml}$ na região précecal, enquanto no IG atingiu 5,3 x 10 5 UFC/ML. Da mesma forma a concentração de AGV foi maior no $\mathrm{IG}(96,3 \mathrm{mmol} / \mathrm{l})$ do que na região pré-cecal $(8,8 \mathrm{mmol} / \mathrm{l})$, confirmando a reduzida capacidade de aproveitamento da fibra na região pré-cecal (Fombelle et al., 2003)

Coenen et al (2006) mensurando a exalação dos gases $\left(\mathrm{H}_{2}\right.$ e $\left.\mathrm{CH}_{4}\right)$ após ingestão de dietas com diferentes fontes de carboidratos para equinos (amido, inulina, pectina e celulose) observaram que a inulina e o amido são fermentados rapidamente na região pré-cecal, baseados em dados de fermentação in vitro, taxa de desaparecimento da MS e produção de gases. Observou-se resposta rápida da população microbiana pré-cecal a presença do amido e inulina. Entretanto a pectina mesmo sendo uma fonte facilmente fermentável, este tipo de carboidrato não propiciou aumento na concentração de $\mathrm{H}_{2}$ neste segmento.

Grande parte da absorção de glicose ocorre na região proximal do ID. Os fatores que diminuem o tempo de retenção da dieta neste segmento podem afetar a absorção da glicose, como o tipo e quantidade de forragem da dieta, por afetar a taxa de passagem da dieta neste compartimento. A quantidade de enzimas também pode afetar a digestão do amido, porém não se tem relato de aumento na secreção de enzimas atribuídas à dieta. Kienzle et al (1994) observou aumento na secreção de amilase em dietas contendo grãos quando comparado com dietas a base de feno. Estes autores observaram que a secreção enzimática varia entre os indivíduos, concluindo que mais estudos são necessários para definir a secreção enzimática em equinos.

\section{Intestino grosso}

O intestino grosso (IG) do cavalo compreende seções volumosas, bem articuladas e compartimentalizadas. Na porção distal do íleo, encontra-se o ceco, com capacidade media de 25 a 35 litros, ligado ao cólon ventral direito, o qual, juntamente com o cólon ventral esquerdo e as porções esquerda e direita do cólon ventral, compõem o cólon maior, que mede cerca de 3 a 4 metros e tem o dobro da capacidade do ceco. Os quatro segmentos do cólon estão conectados por dobras, conhecidas como flexuras que tem como ponto de relevância a mudança na população microbiana de região para região.

A digestão no ceco e cólon ventral depende quase que totalmente da atividade de bactérias e protozoários ciliados. Neste compartimento a mucosa não tem secreção enzimática, secretando apenas muco.

O tempo médio de retenção (TMR) do alimento no IG varia com sua natureza, assim dietas a base de feno o TMR foi de 21 à 40h, diminuindo dentro desta faixa à medida que a ingestão aumentava. Grande diminuição no TMR foi associado a menores coeficientes de digestibilidade (Frape, 2008).

Nos cavalos o tempo de passagem é influenciado pela forma física da dieta. Assim dietas peletizadas têm tempo de passagem mais rápido do que o feno picado ou longo, e capim fresco tem passagem mais rápida do que o feno.

As floras do ceco e cólon são principalmente bactérias, as quais, em animais recebendo alimentação podem atingir de $0,5 \times 10^{9}$ a $5 \times 10^{9} / \mathrm{g}$ de conteúdo. Como a quantidade de amido é diminuta, quando comparada ao rúmen, a taxa de fermentação nos equinos é menor. O número de bactérias 
celulolíticas varia entre 104 e $107 \mathrm{~g} / \mathrm{mL}$ no IG (Julliand et al., 2001) com maior abundância no ceco do que no cólon, indicando que o ceco é provavelmente o principal sítio de digestão de fibras. Foram identificadas as espécies Ruminococcus flavefaciens, Ruminococcus albus and Fibrobacter succinogenes como as principais bactérias celulolíticas no ceco do eqüino. Daly et al. (2001) citaram Clostridium spp., Ruminococcus spp., Butyrivibrio spp. e Eubacterium spp. como as mais importantes bactérias celulolíticas e organismos fibrolíticos. Ainda é bastante escasso o conhecimento sobre a atividade das bactérias eqüinas que digerem as varias frações da fibra dos alimentos.

Os protozoários (fauna) atingem cerca de $10^{-4}$ da população microbiana, ou seja, de $0,5 \times 10^{5}$ a $5 \times 10^{5} / \mathrm{mL}$ de conteúdo. Já foram descritas 72 espécies de protozoários que povoam o IG do eqüino, sendo que alguns apresentam tendência por compartimentos. Os gêneros de destaque são: Buetschilia, Cycloposthum, Blepharocorys e Paraisotricha. Sabe-se que a contribuição para o metabolismo é inferior ao das bactérias.

Segundo Frape (2008), a defaunação não causou nenhum efeito sobre o número de bactérias e na digestibilidade da celulose em equinos, apenas diminuiu levemente a digestibilidade da MS. Moore \& Dehority (1993) estudando o efeito de dietas e da defaunação na digestibilidade da dieta e na concentração microbiana do ceco e cólon de equinos, observou que a defaunação não apresenta efeito sobre a concentração total quanto na concentração de bactérias celulolíticas no ceco e no cólon. A defaunação não afetou a concentração de fungos no ceco, porém houve ligeiro aumento da concentração no cólon. A concentração de fungos celulolíticos total é aproximadamente 10 vezes maior no cólon do que no ceco. Os protozoários parecem não ter um papel essencial sobre a fermentação dos ingredientes no IG do eqüino.

A porção do ceco e cólon ventrais são as áreas de maior concentração de bactérias digestoras de celulose. Em animais recebendo duas dietas por dia, a população de microorganismos do IG do eqüino pode ser alterada mais de 100 vezes durante um período 24horas. Tais flutuações se refletem a mudança na disponibilidade de nutrientes (amido e proteína) e conseqüentemente nas alterações de $\mathrm{pH}$. Segundo Moore-colyer (1998) a alteração na dieta e a relação concentrado: feno não apenas terá grandes efeitos sobre o número de microrganismos, mas também influenciará consideravelmente a distribuição de espécies no IG.

Grandes refeições de concentrado levam a respostas glicêmicas elevadas que podem precipitar anormalidades comportamentais, ao passo que o alimento fibroso diminui esta resposta. A fibra estimula o peristaltismo e é catiônica, o que diminui o risco de acidose metabólica. Duren (2000) cita que cavalos alimentados com feno e sal mineral, antes do exercício de resistência (enduro), apresentam $73 \%$ mais água no trato digestório após o exercício e 33\% mais eletrólitos, do que animais alimentados com dietas com baixo nível de fibra. Esta reserva de água e eletrólitos pode prevenir os animais de provas de resistência a desidratação e desbalanço mineral, situações que cotidianamente acometem grande número de equinos atletas. Outro ponto importante da fração fibrosa da dieta é a manutenção do suprimento sanguíneo ao IG, fazendo com que o sangue não seja todo dirigido a periferia (musculatura). Esta situação mantém ativo o IG e previne cólicas nos animais.

A degradabildiade é dependente da composição da parede celular do alimento, sendo geralmente avaliada sobre os polissacarídeos não amiláceos (PNA), constituídos pelos monômeros: arabinose, galactose, ácidos urônicos, glicose e xilose, sendo os três primeiros mais degradáveis pela microflora microbiana do IG dos equinos.

Como produto da fermentação microbiana obtem-se ácidos graxos de cadeia curta, principalmente, no caso das forragens, o acetato e o butirato, sendo que a obtenção de propionato e ácido lático ocorre principalmente quando crescentes porções de amido não digerido atingem o IG. Frape (2008) cita que 7\% da glicose de pôneis derivam do propionato. O eqüino tem a capacidade de produzir cerca de $1 \mathrm{~g} \mathrm{AGV/Kg} \mathrm{PV.}$

A degradação microbiana parece ocorrer em taxa mais rápida no ceco e cólon ventral que no dorsal, e é mais rápida ainda quando é utilizado amido do que carboidratos estruturais. $\mathrm{O}$ pH ótimo, tanto para a atividade microbiana como para absorção, é de aproximadamente 6,5. A abosrção dos AGV é depende do antiporte de $\mathrm{Na}^{+} / \mathrm{H}^{+}$bem como das trocas de $\mathrm{Cl}^{-} / \mathrm{HCO}^{-}$. Nos equinos o butirato passa prontamente para a corrente sangüínea. $\mathrm{O}$ ácido lático produzido no estômago não é absorvido e utilizado no ID, mas ao atingir o intestino grosso parte é absorvida juntamente com o produzido no local e parte é metabolizada a propionato pelas bactérias (Frape, 2008).

Segundo Hoffman (2003), no IG serão digeridos os carboidratos que não foram aproveitados no ID produzindo ácidos graxos voláteis, sendo o acetato, propionato $\mathrm{e}$ butirado e em menor quantidade o lactato e valerato. A microflora produz celulase que é responsável pela quebra das ligações â 1,4 presentes na celulose e na hemicelulose. A ligno-celulose poderá ser quebrada por fungos à celulose, e a lignina será excretada nas fezes sem aproveitamento. A concentração dos ácidos graxos produzidos depende do 
substrato e primordialmente da relação concentrado: volumoso da dieta. Elevadas quantidades de grãos na dieta levam a maior produção de propionato e lactato em detrimento a produção de acetato. Quantidades excessivas de carboidratos rapidamente fermentáveis (amido) em quantidades já mencionadas de $0,4 \%$ do PV ou ainda de $0,2 \%$ do peso vivo, favorecem a proliferação de Lactobacilli e a produção de lactato. O acúmulo de lactato pode superar a capacidade tampão do ceco e cólon e diminuir o $\mathrm{pH}$ do meio. Animais em pastejo mantém o pH do IG em torno de 6,4 à 6,7. O pH 6 já foi considerado acidose sub-clínica, e inferior a 6 associado a diarréias osmóticas, crescimento de bactérias indesejadas e aumento da possibilidade de endotoxemia e laminite.

A absorção dos ácidos graxos voláteis no IG ocorre na forma de ácidos livres, por difusão passiva através da mudança do gradiente de pH. A taxa de absorção é inversamente proporcional ao peso molecular, sendo inicialmente absorvido acetato, propionato, butirato e lactato. A absorção é essencial para a manutenção do $\mathrm{pH}$ do meio (acima de 6) o qual é requerido para manutenção das bactérias responsáveis por fermentar as fibras. Uma vez absorvidos os ácidos graxos passam pelo sistema portahepático e circulam como ânions neutros no $\mathrm{pH}$ sanguíneo. $\mathrm{O}$ acetato e o butirato podem fornecer carbonos para a síntese de lipídios, enquanto o propionato é substrato gliconeogênico e contribui para o metabolismo da glicose.

Reynolds (2008) relata que são necessário novos estudos sobre o aproveitamento do amido no IG dos equinos. $\mathrm{O}$ amido do milho fermentado no IG produz cerca de $75 \%$ da energia produzida no ID, entretanto a presença do amido no IG afeta a digestibilidade da fibra, reduzindo a energia disponível da dieta. Dietas pobres em fibra podem prejudicar a digestão da fração fibrosa. Dietas com menos de $6 \%$ de fibra mostram ter maior propensão a causar cólicas e distúrbios gástricos, quando comparado a dietas com 12 a $14 \%$ de fibra.

\section{Avaliação dos carboidratos na dieta de equinos}

Os carboidratos podem ser agrupados em carboidratos fibrosos - celulose e hemicelulose, que, juntamente com a lignina, compõem a parede celular vegetal - e não-fibrosos, que incluem amido, mono, di e oligossacarídeos, frutosanas, pectinas, galactanos e â-glucanos. Segundo Kronfeld (2001), Hoffamn (2003) e NRC (2007), este tipo de avaliação é mais adequado à fisiologia digestiva dos ruminantes que à dos equinos, pois diferenças importantes no processo de digestão entre as espécies devem ser observadas, em virtude da diferença na compartimentalização do trato digestório, o que resulta em variações na digestibilidade dos alimentos.

Segundo o NRC (2007) os carboidratos são a principal fonte de energia na dieta de equinos. Os carboidratos são organizados pelo seu grau de polimerização e são referidos como mono, di, oligo e polissacarídeos. São monossacarídeos de importância nutricional a glicose, frutose, galactose, manose, arabinose e xilose. Os monossacarídeos ocorrem em baixas concentrações livres nas plantas, porém fazem parte de oligossacarídeos (3 a 10 polimerizações). São destaques de oligossacarídeos na dieta de equinos a rafinose, estaquiose e frutooligossacarídeo (FOS). O termo frutanas é utilizado para descrever carboidratos contendo múltiplas unidades de frutose. E o FOS e a inulina são tipos de frutanas.

Também são polissacarídeos o amido e a celulose (os dois mais comuns nas dietas de equinos), bem como a pectina e hemicelulose.

A maioria dos carboidratos contém similares concentrações de energia bruta, sendo variável em energia digestível e energia metabolizável. Os monossacarídeos digeridos e absorvidos no ID produzem mais energia do que os carboidratos digeridos pela flora do IG. O tipo de ligação entre os monômeros tem grande influência sobre o sítio de utilização, sendo as ligações á 1,4 e á 1,6 do amido e maltose (ocorrem no ID) enquanto as ligações â (presentes na celulose e hemicelulose) necessitam da fermentação microbiana, pois o organismo do eqüino não produz tal enzima. A estaquiose, rafinose, â-glucanas e pectina também são resistentes a digestão enzimática dos equinos.

Vários sistemas foram desenvolvidos para classificar os carboidratos de plantas, alguns deles levando em consideração apenas a composição botânica da planta e outras levam em consideração a implicação na nutrição humana e animal. O sistema mais comum utilizado foi desenvolvido por Van Soest em 1960, o qual separa o ingrediente pelo o que é solúvel em detergente neutro e a fibra solúvel em detergente neutro (FDN), sendo este constituido por celulose, parte da hemicelulose e lignina. Por muitos anos os carboidratos não estruturais (CNE) foram obtidos pela subtração simples da FDN, proteína bruta, extrato etéreo e materia mineral da MS.

Atualmente utilizam-se os carboidratos não-fibrosos (CNF) para definir o que antes era conhecido como CNE, o qual engloba mono e dissacarídeos, oligossacarídeos (incluindo as frutanas) e amido. São observadas diferenças entre CNE e CNF principalmente em alimentos ricos em pectinas. Hoffman et al (2001) sugerem o seguinte sistema de partição de carboidratos para equinos: (1) fração de carboidratos hidrolisáveis $(\mathrm{CHO}-\mathrm{H})$, os quais podem ser 
digeridos no ID (hexoses, dissacarídeos, alguns oligossacarídeos e amido não resistente); (2) Carboidratos rapidamente fermentáveis (CHO-FR) os quais são rapidamente disponibilizados para a fermentação dos microrganismo (pectinas, frutanas, e alguns oligossacarídeos não digeridos no ID, além do amido resistente e a hemicelulose solúvel em detergente neutro) e (3) carboidratos lentamente fermentáveis (CHO-FL), incluindo celulose, hemicelulose, ligno-celulose, os quais no intestino grosso produzem principalmente acetato.

Hoffman (2003) cita que, até que algum método analítico seja desenvolvido para avaliação de todas as frações carboidrato, pode-se considerar os CNF como carboidratos hidrolisáveis, os carboidratos de fermentação rápida (obtido pela diferença de $\mathrm{CNF}$ e CNE) e carboidratos de fermentação lenta (representados pelo FDN). Os carboidratos não fibrosos englobam tanto os carboidratos hidrolisáveis como os de fermentação rápida. A fração hidrolisável de carboidratos não estruturais corresponde a 1/5 dos CNF do feno, $1 / 3$ do CNF da pastagem, $1 / 2$ à $2 / 3$ dos CNF de concentrados ricos em fibras e $100 \%$ do CNF de dietas com mistura de grãos (em inglês, sweet feed). Os carboidratos de fermentação rápida representam cerca de 5-50\% (base de MS) das gramíneas. A ligação â-2,6 glicosídica das frutanas não é quebrada pelas enzimas dos mamíferos, assim as frutanas são rapidamente fermentáveis no IG. Um aumento abrupto de frutanas é notado de um dia para o outro em gramínea de crescimento rápido e de hora em hora, quando a composição da planta muda do período da noite para o dia ou ainda de ambiente escuro para o claro.

Os carboidratos estruturais são importantes fontes de energia para equinos. A produção de AGV no ceco é capaz de suprir $30 \%$ da energia de mantença do eqüino, e somados aos produzidos no cólon, são capazes de nutrir os equinos em pastejo exclusivo. O acetato é o principal AVG produzido e pode ser utilizado diretamente para energia. Estudos mostraram que o acetato pode ser utilizado pelo posterior dos equinos e fornecer-lhes $30 \%$ da energia necessária (Pethick et al, 1993), e quando não utilizado imediatamente provavelmente é utilizado para síntese de ácidos graxos de cadeia longa, os quais podem ser estocados ou secretados no leite de éguas em lactação. O propionato produzido na fermentação bacteriana pode ser utilizado para a síntese de glicose no fígado, através da gliconeogênese, processo importante para manutenção da glicemia de herbívoros restritos. A função do butirato nos equinos ainda não foi totalmente estudada.

Moore \& Dehority (1993) reportaram mínima diferença entre as bactérias celulolíticas cecais de pôneis recebendo dietas com $90 \%$ de feno e $10 \%$ de concentrado e $60 \%$ de feno e $40 \%$ de concentrado. De qualquer forma, dietas ricas em concentrado estão associadas a aumento da população bacteriana e de protozoários no cólon. A composição da dieta afeta a produção de $\mathrm{AGV}$, sendo que dietas a base principalmente de forragens o principal $\mathrm{AGV}$ produzido é o acetato. A medida que se introduz milho na dieta ocorre aumento na produção de propionato (Medina et al, 2003) e na concentração de acido lático observando-se queda de pH no ceco e cólon do eqüino.

Alguns estudos no campo de "Fibra efetiva" e "FDN efetivo" começaram a ser discutidos em equinos, como já ocorre nos ruminantes, mas ainda são necessários maiores estudos para a determinação adequada da quantidade de fibra, do tipo de digestão e da saúde geral do TD dos equinos.

\section{Ingredientes volumosos para dietas de equinos}

O estudo de ingredientes fibrosos para dieta de equinos é de suma importância, pois estes são a base da dieta desta espécie.

Alguns trabalhos nacionais avaliaram a digestibilidade de volumosos para equinos (Furtado et al, 1999, Perali et al., 2001, Almeida et al, 1999, Figueiredo et al, 1999 e Moretini et al, 2004), os quais estão apresentados na Tabela 1.

Os trabalhos nacionais apresentados mostraram que a digestibilidade média de volumosos apropriados para equinos é de $50 \%$ tanto para a proteína como para a energia. A adição de um ingrediente concentrado, em quantidades não excessivas, favorece a digestibilidade do volumoso.

Estudos mais recentes no Brasil, sugeriram novas opções de alimentos volumosos para equinos. Quadros et al (2004) com o objetivo de avaliar nutricionalmente a casca de soja alimentação de equinos e sobre o crescimento de animais jovens, utilizou dietas com 0,33,3; 66,6 e 100\% de substituição do feno de Tifton 85 por casca de soja. Sobre a digestibilidade, foi observado aumento linear nos coeficientes de digestibilidade de MS, FB, FDN e FDA, atribuídos a maior quantidade de pectina fornecida pela casca de soja. Não houve efeito dos tratamentos sobre o ganho de peso médio diário dos cavalos, entretanto o ganho de peso $(0,634 \mathrm{~kg} / \mathrm{dia})$ foi superior ao recomendado pelo NRC (1989). Tais autores concluíram que dietas de equinos em crescimento podem ser formuladas com substituição parcial ou total do feno de Tifton 85 por casca de soja, porém sobre os parâmetros de desempenho sugerese inclusão de apenas $40 \%$ de casca de soja a dieta.

Braga et al. (2008) avaliaram níveis mínimos e seguros de fibra na alimentação dos equinos utilizando dois níveis 

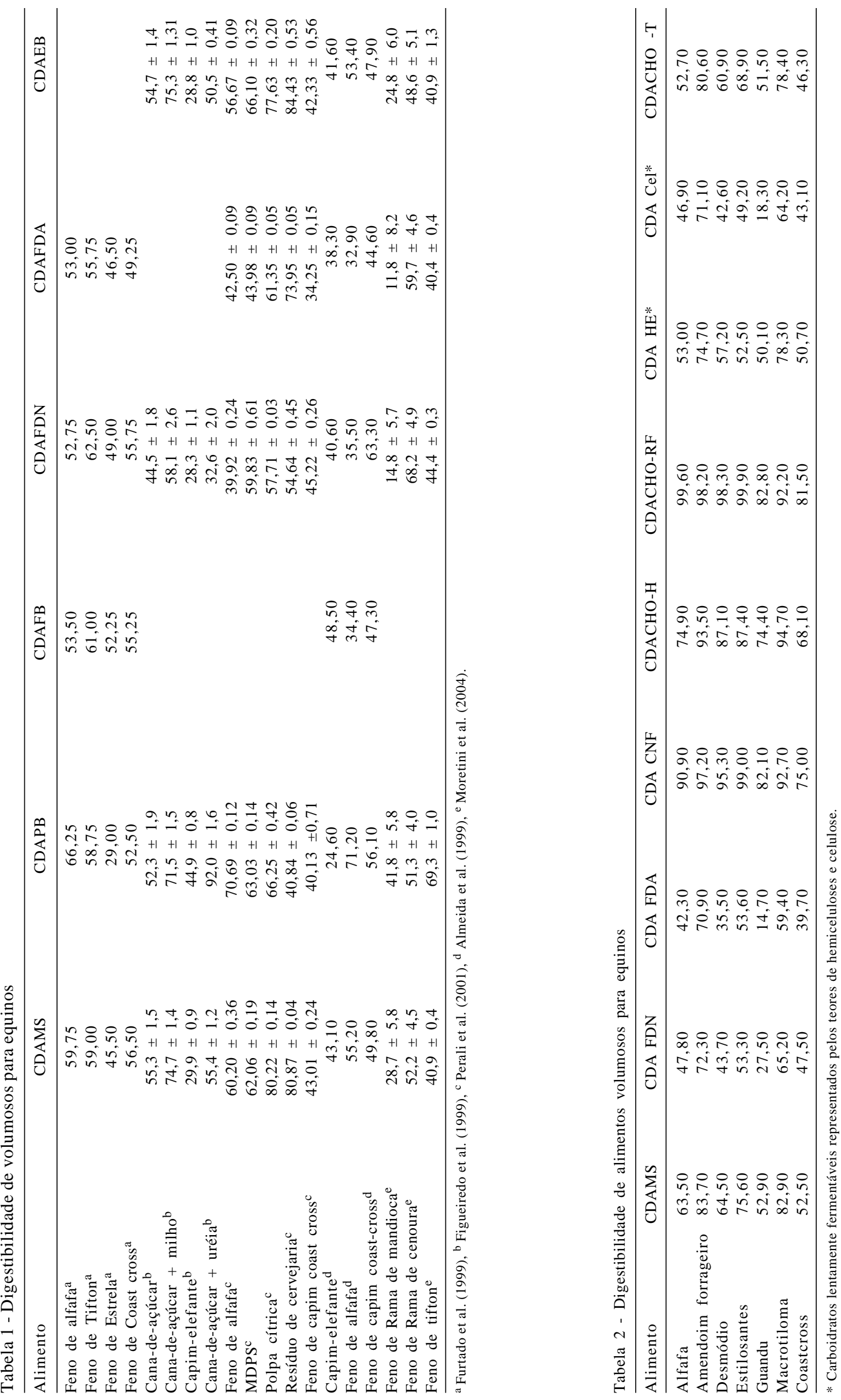
de FDN (25 e 35\%), provenientes de duas proporções de volumoso:concentrado (50:50 e 60:40). Os autores observaram que nas dietas houve depleção na digestibilidade da fibra, sendo que na dieta com $25 \%$ de FDN aumentou o teor plasmático de fibrinogênio sugerindo a predisposição de cólica e laminite.

Morgado et al (2009), estudando a digestão de carboidratos de alimentos volumosos para equinos (Tabela 2) concluíram que os equinos apresentam alta eficiência na digestão total dos carboidratos não fibrosos e de suas frações nos volumosos. A avaliação da composição dos carboidratos fibrosos e não fibrosos são um bom indicativo do valor nutricional do alimento e pode ser incluída na avaliação da qualidade do alimento para equinos. $\mathrm{O}$ amendoim forrageiro mostrou-se uma alternativa de volumoso na nutrição de equinos.

Na literatura internacional encontram-se vários estudos sobre a importância da fibra na dieta de equinos. Considerando a excessiva quantidade de concentrado que algumas categorias de equinos recebem em sua dieta, recomenda-se que a quantidade máxima de amido que atinge o IG não exceda a $2-2,5 \mathrm{~g} / \mathrm{kg}$ PV, para evitar distúrbios gástricos (Kienzle, 1994).

Kalsson et al (2000) avaliando a digestibilidade de dietas compostas por feno e aveia, relataram que a medida que aumentou a quantidade de aveia na dieta houve queda na digestibilidade da fração fibrosa e aumento da digestibilidade da proteína, amido e energia bruta. Estes autores citaram que existe efeito associativo negativo na adição de aveia ao volumoso, principalmente quando se considera a fração fibra. Foi observado também pequeno aumento na digestibilidade dos nutrientes com a inclusão de $20 \%$ de aveia, o que foi atribuído ao estimulo a microflora do IG e por conseqüência aumento na digestibilidade da fração fibra.

Quando se considera o efeito associativo dos ingredientes da dieta deve-se levar em consideração o tipo e a qualidade do alimento fornecido, além da seqüência de arraçoamento. O fornecimento do volumoso antes do concentrado mostra-se como mais indicado pois estimula a produção de saliva, obtenção de melhor mistura da ingesta no estômago e além de otimizar a passagem desta para o IG (Meyer, 1992). Tisserand (1992) sugere que em dietas com predominância de grãos ou concentrado o fornecimento de volumoso e concentrado seja feito em separado. Neste sentido, Kienzle (1994) cita que quando o grão ou concentrado é fornecido sozinho menor porcentagem de amido é quebrado, assim maiores quantidade de amido adentram o IG favorecendo a queda no $\mathrm{pH}$ e com isso deprimindo a digestibilidade da fibra.

Hussein et al (2004) estudaram o efeito da suplementação (0,2\% PV-cevada, milho, aveia e aveia sem casca) em dieta a base de alfafa (1\% PV). A introdução de grãos na dieta aumentou a digestibilidade $\mathrm{CNE}$ e promoveu queda no $\mathrm{pH}$. As maiores concentração de ácidos graxos voláteis foram observadas nas dietas a base de cevada e aveia sem casca, mesmos ingredientes que promoveram maior produção de lactato fecal. Grãos podem ser adicionados até $0,2 \%$ do peso vivo por refeição, sem afetar negativamente a digestibilidade dos nutrientes e dispor os cavalos a riscos de cólica e laminite. A utilização de aveia sem casca é uma alternativa para aumentar a energia da dieta, por aportar amido digestível no ID e também aumentar o aporte protéico a dietas a base de gramíneas de baixa qualidade proteíca.

Kienzle et al (2002) observaram maiores coeficientes de digestibilidade da fração fibrosa de dietas compostas por volumosos acrescidos de concentrado, o que foi atribuído ao influxo de carboidratos fermentáveis (fibra fermentável, amido e açúcares não digeridos) ao IG aumentando a atividade microbiana, inclusive a celulolítica. Tais autores concluíram que a interação entre os ingredientes são consideravelmente importantes em dietas contendo volumosos de baixa digestibilidade.

Nos últimos anos, em virtude da alta relação concentrado: volumoso das dietas de equinos estarem associadas, dentre vários fatores, com os distúrbios do TD, observou-se alguns estudos em busca de aumentar a disponibilidade de energia com base na utilização de volumosos mais energéticos, como a polpa de beterraba, a casca de soja e a polpa cítrica. A casca de soja é um ingrediente rico em pectinas, celulose e hemicelulose, e pobre em lignina, que apresenta boa palatabilidade e digestibilidade.

Duren (2000) cita que a fibra, na forma de volumoso/ feno, é excelente fonte de energia para equinos submetidos a provas de enduro. Em adição a fibras habituais, surgem as "superfibras" presentes na polpa de beterraba e na casca de soja, as quais apresentam as mesmas características benéficas da fibra em geral, porém apresentam maior concentração de energia, atribuídas a elevada concentração de fibra (PNA) e baixa lignina destes produtos, sendo assim, mais disponíveis aos microrganismos. Estes ingredientes produzem quantidades de energia semelhantes à aveia, porém são mais seguros por não produzirem os mesmos sintomas do excesso de amido no IG.

Moore-Colyer et al (2002) verificaram que os ingredientes volumosos que geraram maiores quantidades de nutrientes 
no trato digestório total de equinos foram a polpa de beterraba, seguidos de casca de soja, cubos de feno e casca de aveia: aveia sem casca. Porém a polpa de beterrada, dentre os ingredientes avaliados, é o que apresenta menor digestibilidade no intestino delgado e menor digestibilidade da proteína.

Coverdale et al (2004), estudando a casca de soja como fonte alternativa de fibra, utilizou dietas a base de alfafa e gramíneas com substituições de 0,25, 50 e 75\% de casca de soja. Houve aumento linear na produção de ácidos graxos voláteis à medida que a casca de soja foi introduzida a dieta, com aumento da produção de propionato, sendo que a produção de butirato decresceu, fato também observado na relação acetato: propionato. A digestibilidade de MS, MO, FDN, FDA, Celulose e hemicelulose não apresentou diferença entre os tratamentos, porém a digestibilidade da fração nitrogenada diminuiu atribuído a formação da maior massa microbiana. O pH cecal decresceu $(7,0$ para 6,75$)$. Os autores concluíram que a casca de soja estimula a fermentação fecal constituindo-se fonte alternativa de fibra para equinos. A maior produção de propionato pode favorecer a gliconeogênese por ser um de seus substratos, além de representar menor perda de energia na forma de gás.

A importância do conhecimento do valor nutricional adequado de volumosos para equinos foi demonstrado por Hoffman et al (2001), onde mensuraram os carboidratos hidrolisáveis e compararam estes valores com valores de carboidratos não estruturais (CNE) para testar por predição a concentração de carboidratos hidrolisáveis (CHO-H) na forragem e para avaliar a variação sazonal da pastagem. Sugeriram a seguinte equação: $\mathrm{CHO}-\mathrm{H}=0.154 \times \mathrm{NSC}+$ $0.00136 \times$ NSC2, R2 $=0.98$. Com o uso do NIRS, obteve-se concentração média de $48 \pm 3,5 \mathrm{~g} / \mathrm{kg}$ de CHO-H nas pastagens. Forragens colhidas no outono tiveram variação de $31 \%$ para CHO-H e CHO- FR.

Watts (2004) estudando o manejo de forragens e pastagens para equinos com laminite, observou que as frutanas podem induzir os equinos a laminite. Elevadas

Tabela 3 - Concentração - carboidratos não estruturais de volumosos para equinos

\begin{tabular}{lcc}
\hline & Média & Normal \\
\hline Forragem de gramíneas frescas & 18,70 & 10,59 \\
Forragem fresca da família da Bermuda & 10,20 & 6,74 \\
Feno de gramínea & 13,26 & 11,12 \\
Feno de Bermuda & 13,26 & 9,15 \\
Feno de Alfafa & 11,39 & 9,96 \\
Polpa de Beterraba & 12,24 & 9,44 \\
Farelo de trigo & 30,19 & 20,92
\end{tabular}

2003 Feed Composition Library at Dairy One Forage Lab, Ithaca, NY; Complete listing at http://www.dairyone.com/Forage/FeedComp/default.asp concentrações de frutanas podem ser encontradas em gramíneas que são sujeitas a rápidas modificações do meio ambiente, as quais contêm níveis superiores a 35\% da MS em açucares, amido e frutanas, as quais compõem a fração dos carboidratos não estruturais (CNE). Os fatores que podem influenciar a composição de CNE são gênero e espécie da forragem, temperatura, estatus de nutriente e água, estágio de crescimento e manejo do pastoreio. As plantas C3 (gramíneas de clima temperado-aveia, triticale, trigo e centeio e também gramíneas como Festuca sp, Phleum sp,) tem maior capacidade de depositar CNE (frutanas) quando comparado com as plantas C4. Para maior deposição de frutanas, as temperaturas devem variar entre $10^{\circ}$ e $5^{\circ} \mathrm{C}$, durante o dia e noite respectivamente. São poucas as regiões no Brasil, que atingem tais temperaturas, assim podemos considerar que a concentração de frutanas nos volumosos tropicais será inferior, quando comparado aos de clima temperado. As gramíneas $\mathrm{C} 4$ produzem pouco ou nenhuma frutana e armazenam energia na forma de amido, sendo alguns exemplos deste grupo: Cynodon dactylon, Paspalum sp., Andropogon sp., Panicum virgatum, que tem como característica ainda maior acumulo de hemilcelulose do que as do grupo C3. As gramíneas C3 acumulam os CNE principalmente no caule. Após a floração é o ponto de maior acumulo de CNE. Para os fenos, a concentração de CNE reflete o momento e a hora do corte, sendo que os cortes feitos no período da tarde e em época seca promovem maior acumulo de CNE. Na Tabela 3 encontram-se indicadas algumas concentrações de CNE de volumosos para equinos.

Longland et al. (2006), estudaram os efeitos do ambiente sobre o acúmulo de carboidratos não estruturais (amido, frutanas e açúcares simples) em pastagem, estimaram o possível consumo de CNE em animais em pastejo, além de sugerirem estratégias para diminuir a concentração de CNE nas pastagens e manejos que podem reduzir a ingestão de CNE por equinos predispostos a laminite. Estes pesquisadores relataram que existe evidência de relação entre a laminite e a rápida ingestão de $\mathrm{CNE}$, bem como o consumo excessivo de CNE pode causar distúrbios digestivos associados a rápida fermentação deste substrato e desordens metabólicas crônicas associadas a elevadas respostas glicêmicas e insulinêmicas. Como as frutanas não são digeridas enzimaticamente e pouco delas é aproveitada pela fermentação estomacal e do intestino delgado, considera-se que ela adentre praticamente intacta o intestino grosso. A laminite pode estar associada ao excesso de amido e frutanas no IG, potencializa ação das bactérias lácticas, reduzindo o pH do meio, levando o animal a acidose 
no IG; outro ponto importante é a resistência a insulina em equinos segundo o qual é possível pelo aumento na glicose circulante quando a insulina é baixa, leva a um menor suprimento de glicose as células, incluindo as células do casco. Pastagens apresentam maiores concentração de CNE no final da tarde-início da noite (240g/kg MS) e menores concentrações no início da manhã (160 g/kg MS). A alta seletividade dos equinos faz com ingiram sempre as plantas mais doces, e que não consumam a forragem na área onde defecaram. Sugere-se que o eqüino ao consumir as sementes das gramíneas estas aportem quantidade de amido para o IG na ordem de $250 \mathrm{~g}$ (cavalo de $500 \mathrm{~kg}$, consumindo 2,5\% PV), rapidamente disponibilizados para o IG. Algumas estratégias são sugeridas para a menor ingestão de CNE tais como: não permitir acesso do cavalo nas primeiras horas da manhã, pastejar em pastos sombreados, prevenir pastejo em horários de muita luz e baixas temperaturas, principalmente nas épocas de outono e primavera. Estes pesquisadores classificam CNE como o somatório de amido, frutanas, açúcares, pectinas, gomas e mucilagens, ou apenas o somatório da fração açúcar que inclui os açúcares simples e as frutanas. Como animais em situações normais pastejam por 12 a 17h/dia, o aporte de substrato para o intestino é constante. Ainda não se sabe se o constante aporte de CNE estimula a proliferação de bactérias lácticas, reduzindo o pH do IG ou se esta situação é transitória.

\section{Considerações Finais}

Para que o eqüino mantenha fermentação microbiana adequada no TD é necessário promover aporte de fibra, em quantidades adequadas para favorecer a fermentação. Dietas com nível inadequado de fibra e elevado de amido deprimem a fermentação. Assim, sugere-se a utilização de dietas baseadas em volumoso de boa qualidade e a inclusão de fontes de fibra com alta disponibilidade de energia (polpa cítrica, polpa de beterraba, casca de soja). O menor aporte de amido para o eqüino pode prevenir a ocorrência de distúrbios digestivos e metabólicos.

Uma boa alternativa para aumentar a energia da dieta é associar fontes de fibra de fermentação rápida e carboidratos solúveis, favorecendo a geração de energia através do aproveitamento da fibra. É de suma importância identificar qual é o sítio de aproveitamento de cada ingrediente, favorecendo a digestibilidade dos ingredientes e impedindo desequilíbrios nutricionais. Por outro lado, mostra-se importante atentar-se ao uso de CHO solúveis e rapidamente fermentáveis para que os mesmos não promovam sintomas semelhantes aos observados aos do excesso de amido.

Não se pode ignorar a presença e a eficiência do ceco e cólon como agentes funcionais na nutrição dos equinos. $\mathrm{O}$ fracionamento da dieta e a associação adequada das frações amido: fibra, favorece o metabolismo energético dos equinos. A adição de amido a cada refeição não deve ultrapassar 0,2\% do PV do eqüino por refeição.

Em equinos em pastejo é necessário observar o estagio fisiológico da planta. Plantas próximas à floração apresentam maiores concentrações tanto de amido (C4), quanto de frutanas (C3). A estação do ano também deve ser observada, pois nas épocas de primavera e verão a taxa fotossintética é maior e com isso a produção de amido/frutanas é aumentado. Deve-se considerar que ocorre, também, variação diurna, sendo o final da tarde o período de maior acúmulo de $\mathrm{CHO}$, devendo ser evitado o pastejo de animais que apresentam pré-disposiçao a cólicas e laminite. Quando considera-se a avaliação de fenos, devemos tomar como base a época de fenação e seu manejo, pois fenos confeccionados na primavera/ verão e próximos a floração apresentam maiores concentração de $\mathrm{CHO}$.

Existem também outros fatores ambientais de destaque como as áreas de sombreamento ou o tempo de escuro, situações que tornaram menor a taxa fotossintética e com isso a deposição de $\mathrm{CHO}$; o déficit hídrico, que promove maior acúmulo de $\mathrm{CHO}$, quanto a taxa fotossintética é máxima. Por outro lado a fertilidade do solo parece não influenciar efetivamente a concentração de $\mathrm{CHO}$ das plantas.

A quantidade de FDN na dieta deve ser conhecida, evitando a depleção da digestibilidade da fibra. Dietas com baixo nível de fibra deprimem a fermentação microbiana no IG. Assim as dietas de equinos devem manter pelo menos $12 \%$ de fibras na dieta.

Faz-se necessário desenvolver um método de análise do fracionamento dos carboidratos para equinos, uma vez que o mais aplicável atualmente foi desenvolvido para uso em bovinos, e não se aplica totalmente a fisiologia e o metabolismo dos equinos.

\section{Recomendações}

- Basear a dieta de equinos no fornecimento máximo de volumoso que o estágio fisiológico ou atlético permite;

- Quando necessário, aumentar a energia da dieta, utilizar volumosos com maior densidade energética, como a casca de soja e a polpa cítrica; 
Fornecer diferentes fontes de volumosos, com qualidades nutricionais diferentes, pois, desta forma, a dieta se torna nutricionalmente mais densa e segura;

Não fornecer dietas com menos de $6 \%$ de FDN, visando evitar distúrbios metabolismos;

Fornecimento mínimo de $12 \%$ de fibra na dieta;

Animais com restrição no consumo de fibra, como é o caso de cavalos de alto desempenho, avaliar a utilização de ingredientes facilmente fermentáveis, como a casca de soja;

Utilizar efeito aditivo positivo do uso de volumoso e grãos. Acrescentar grãos em quantidades moderadas para favorecer a flora e fauna do IG;

Utilizar grãos na dieta de animais atletas visando à reposição do glicogênio muscular e hepático;

- Para animais em pastejo, consumindo determinadas espécies forrageiras, observar a ocorrência do consumo de grandes quantidades de amido como de frutanas, as quais podem ocasionar laminite e resistência a insulina ou sensibilidade a insulina.

\section{Literatura Citada}

ALMEIDA, M.I.V.; FERREIRA, W.M.; ALMEIDA, F.Q. et al. Valor nutritivo do capim-elefante (Penninsetum purpureun, Schum), do feno de alfafa (Medicago sativa, L.) e do feno de capim coast-cross (Cynodon dactylon (L.) Pers.) para eqüinos. Revista Brasileira de Zootecnia, v.28, n.4, p.743-752, 1999

BRAGA, A.B.; ARAÚJO, K.V.; LEITE, G.G. et al. Níveis de fibra em detergente neutro em dietas para eqüinos. Revista Brasileira Zootecnia, v.37, n.11, p.1965-1972, 2008.

COENEN, M.; MO“ BELER, A.; VERVUERT, I. Fermentative gases in breath indicate that inulin and starch start to be degraded by microbial fermentation in the stomach and small intestine of the horse in contrast to pectin and cellulose. Journal of Nutrition, v.136, p.2108S-2110S, 2006.

COVERDALE, J.A.; MOORE, J.A.; TYLER, H.D. et al. Soybean hulls as an alternative feed for horses. Journal Animal Science, v. 82, p.1663-1668, 2004.

DALY, K.; STEWART, C.S.; FLINT, H.J. et al. Bacterial diversity within the equine large intestine as revealed by molecular analysis of cloned 16S rRNA genes. FEMS Microbiology Ecology, v.38, p.141-151, 2001.

DUREN, S. Feeding the endurance horse. In: PAGAN, J.D. (Ed.). Advances in equine nutrition. Nottingham: Nottingham University Press, 2000. p.351-363.

FIGUEIREDO, D.M.; ARAÚJO, K.V.; LIMA, J.A.F. et al. Valores de digestibilidade de alimentos volumosos para eqüinos. Revista Brasileira de Zootecnia, v.28, n.4, p.766-772, 1999.

FOMBELlE, A.; VARLOUD, M.; GOACHET, A.-G. et al. Characterization of the microbial and biochemical profile of the different segments of the digestive tract in horses given two distinct diets. Journal of Animal Science, v.77, p.293$304,2003$.

FRAPE, D. Nutrição \& alimentação de eqüinos. 3.ed. São Paulo: Roca, 2008. 602p.

FURTADO, C.F.; CABRERA, L.; FONSECA, N.A.N. et al. Avaliação da digestibilidade aparente de fenos de gramíneas e de leguminosa para eqüinos. Acta Scientiarum, v.21, n.3, p.651-655, 1999.

HOFFMAN, R.M. Carbohydrate metabolism in horses. In: Recent advances in equine nutrition. Ithaca: International Veterinary Information Service, 2003.

HOFFMAN, R.M.; WILSON, J.A.; KRONFELD, D.S. et al Hydrolyzable carbohydrates in pasture, hay, and horse feeds: Direct assay and seasonal variation. Journal of Animal Science, v.79, p.500-506, 2001.

HUSSEIN, H.S.; VOGEDES, L.A.; FERNANDEZ, G.C.J. et al. Effects of cereal grain supplementation on apparent digestibility of nutrients and concentrations of fermentation end-products in the feces and serum of horses consuming alfalfa cubes. Journal of Animal Science, v. 82, p.1986-1996, 2004.

JULLIAND, V.; FOMBELLE, A.; DROGOUL, C. et al. Feeding and microbial disorders in horses. 3. Effects of three hay:grain ratios on microbial profile and activities. Journal of Equine Veterinary Science. v.21, p.543-546, 2001

KARLSSON, C.P.; LINDBERG, J.E.; RUNDGREN, M. Associative effects on total tract digestibility in horses fed different ratios of grass hay and whole oats. Livestock Production Science, v.65, p.143-153, 2000.

KIENZLE, E. Small intestinal digestion of starch in the horse. Rev. Me'd. Ve't., v.145, n.2, p.199-204. 1994.

KIENZLE, E.; FEHRLE, S.; OPITZ, B. Interactions between the apparent energy and nutrient digestibilities of a concentrate mixture and roughages in horses. Journal of Nutrition, v.132, p.1778S-1780S, 2002 .

LONGLAND, A.C.; BYRD, B.M. Pasture nonstructural carbohydrates and equine laminitis. Journal Nutrition, v.136, p.2099S-2102S, 2006.

MEDINA, B.; GIRARD, I.D.; JACOTET, E. et al. Effect of a preparation of Saccharomyces cerevisiae on microbial profiles and fermentation patterns in the large intestine of horses fed a high fiber or a high starch diet. Journal of Animal Science, v.80, p.2600-2609, 2002.

MEYER, H. Alimentação de cavalos. 2.ed. São Paulo: Varela, 1995. 303p.

MOORE, B.E.; DEHORITY, B.A. Effects of diet and hindgut defaunation on diet digestibility and microbial concentrations in the cecum and colon of the horse. Journal of Animal Science, v.71, p.3350-3358, 1993.

MOORE-COLYER, M.J.S.; LONGLAND, A.C.L. In vivo apparent digestibility of four types of conserved forage by ponies. Journal of Animal Science, v.71, p.527-534, 2000.

MOORE-COLYER, M.J.S.; HYSLOP, J.J.; LONGLAND, A.C. et al. The mobile bag technique as a method for determining the degradation of four botanically diverse fibrous feedstuffs in the small intestine and total digestive tract of ponies. British Journal of Nutrition, v.88, p.729-740, 2002.

MORGADO, E.S.; ALMEIDA, F.Q.; SILVA, V.P. et al. Digestão dos carboidratos de alimentos volumosos em eqüinos. Revista Brasileira de Zootecnia, v.38, n.1, p.75-81, 2009.

MUHONEN, S. Metabolism and hindgut ecosystem in forage fed sedentary and athletic horses. 2008. 76f. Tese de doutorado. Swedish University of Agricultural Sciences, Faculty of Veterinary Medicine and Animal Science Department of Animal Nutrition and Management Uppsala, Uppsala, 2008.

NATIONAL RESEARCH COUNCIL - NRC. Nutrients requeriments of domestic animals. Washington, D.C.: National Academy of Science, 1989. 64p.

NATIONAL RESEARCH COUNCIL - NRC. Nutrients requeriments of domestic animals. Washington, D.C.: National Academy of Science, 2007. 341p.

PAGAN, J.P.; HARRIS, P.; BARNES, T.B. et al. Exercise affects digestibility and rate of passage of all-forage and mixed diets in thrughbred horses. Journal Nutrition, v.128, p.2704S-2707S, 1998.

PERALI, C. Valores nutricionais de alimentos para eqüinos. Ciência e Agrotecnologia, v.25, n.5, p.1216-1224, 2001.

QUADROS, J.B.Q.; FURTADO, C.E.; BARBOSA, E.D. et al. Digestibilidade aparente e desenvolvimento de eqüinos em 
crescimento submetidos a dietas compostas por diferentes níveis de substituição do feno de Tifton 85 pela casca de soja. Revista Brasileira de Zootecnia, v.33, n.3, p.564-574, 2004.

REYNOLDS, J. A new look at fiber in horse feeds. Equine nutrition in the $21^{\text {st }}$ century, 2007.

TISSERAND, J.L. Fermentation in the hindgut of the horse possibilities of disorders. In: European Konf. u“. Erna“hrung des Pferdes, 1., 1992, Hannover. Proceedings... Hannover: 1992. p. 197-200.

VARLOUD, M.; FONTY, G.; ROUSSEL, A. et al. Postprandial kinetics of some biotic and abiotic characteristics of the gastric ecosystem of horses fed a pelleted concentrate meal. Journal of Animal Science, v.85, p.2508-2516, 2007.

YUKI, N.; SHIMAZAKI, T.; KUSHIRO, A. et al. Cólonization of the stratified squamous epithelium of the nonsecreting area of horse stomach by Lactobacilli. Applied and Environmental Microbiology, v.66, n.11, p.5030-5034, 2000 .

WATTS, K.A. Forage and pasture management for laminitic horses. Clinical Technical Equine Practice, v.3, p.88-95, 2004. 